\title{
IMPROVING LAW STUDENT RESILIENCE: AN AUSTRALIAN
}

\section{PERSPECTIVE}

Doris Bozin, Allison Ballard, Vicki de Prazer ${ }^{1}$

\section{Introduction}

Do university legal clinics, clinical legal educators and health practitioners have a role to play in building the resilience of law students to better equip them to manage their academic studies and their professional lives as they move into legal practice? Given that mental health issues such as depression and anxiety are rife across Australia's law student and legal professional populations, we wondered if developing a legal clinic model in collaboration with a university-based health service would offer one way to address these concerns. To this end, in June 2017, we piloted a university-based healthjustice legal advice clinic at the University of Canberra. The clinic's tripartite goals were to offer practical legal experience to law students, to assess and develop law student resilience through a strong orientation and pastoral care program, and to deliver a pro-bono community legal service to clients (primarily) sourced and referred from the university's medical and counselling service. With the guidance of a

\footnotetext{
${ }^{1}$ Doris Bozin is a Clinical Assistant Professor in Law at the University of Canberra, Dr Allison Ballard is a lecturer at the School of Policing Studies at Charles Sturt University and Vicki de Prazer is a Senior Psychologist at the University of Canberra.
} 
psychologist, the program focused on developing individualised resilience-building strategies incorporated into the academic course of study. Student-focused strategies directed towards preparing them for personal, academic and professional life challenges encompassed a strong pastoral care component developed in collaboration with a psychologist from the health service. We thought this novel approach might better equip law students to deal effectively with their academic studies and future professional lives.

In this article we first consider the relatively poor mental health of Australian law students, lawyers, other legal professionals, the possible reasons for such outcomes and their potentially tragic consequences, before examining some of initiatives taken by the legal profession and the academy to address student and practitioner mental health concerns. Finally, we discuss the case study of the pilot health-justice legal advice clinic in the context of these concerns.

Australian lawyers are more likely than the general population to experience depression, anxiety, ${ }^{2}$ and other forms of mental illness, with almost a third of solicitors and a fifth of barristers suffering from clinical depression. ${ }^{3}$ Lawyers are also more likely than other professionals to self-medicate for stress and sadness using drugs,

\footnotetext{
${ }^{2}$ Laura Helm, Mental Health and the Legal Profession: A Preventative Strategy Final Report (Australia, Law Institute of Victoria, 2014) 6.

${ }^{3}$ Ibid. See also Norman Kelk, Georgina Luscombe, Sharon Medlow, and Ian Hickie, Courting the blues: Attitudes towards depression in Australian law students and legal practitioners (Australia, Brain \& Mind Research Institute, University of Sydney, 2009).
} 
including illicit drugs and alcohol. ${ }^{4}$ They are also at higher risk of heart disease. ${ }^{5}$ In addition, the personality profiles of lawyers are often said to 'cluster around perfectionism and pessimism' characteristics, known risk factors for severe depression. ${ }^{6}$ Suicide on account of severe depression and a reluctance to seek help are also common throughout the legal fraternity, ${ }^{7}$ including across Australia's magistrate and judge cohort. ${ }^{8}$ This dire situation is comparable to that in other common law countries: a study by the Canadian Bar Association for example, suggests the suicide rate of lawyers is five to six times higher than Canada's national average, ${ }^{9}$ while the New York and Chicago Bar Associations report rampant 'unhappiness' and 'discontent' among young lawyers. ${ }^{10}$ In addition, researchers at Johns Hopkins

\footnotetext{
${ }^{4}$ Toni Vozzo, 'New committee focuses on wellbeing of legal profession' (2012) Law Society of South Australia Bulletin 10,10; Janet Chan 'Work-Life Balance' (2015) Law Society of NSW Journal 58,58; Cindy Penrose, 'Another Inconvenient Truth: Mental Health and the legal profession' (2012) 223 Ethos 9; Beyond Blue: The National Depression Initiative, Annual Professions Survey: Research Summary (April 2007) 3 http://www.judicialcollege.vic.edu.au/sites/default/files/2007\%20$\% 20$ Beyond\%20Blue\%20-\%20Annual\%20Professions\%20Survey.pdf.

${ }^{5}$ Martin E. P. Seligman, Paul R.Verkuil, and Terry H. Kang 'Why lawyers are unhappy' (2005) 10(1) Deakin Law Review 49, 53.

${ }^{6}$ Cindy Penrose, 'Another Inconvenient Truth: Mental Health and the legal profession' (2012) 223 Ethos, 8.

${ }^{7}$ Ibid.
}

${ }^{8}$ Noel Towell and Adam Cooper, 'Struggling Magistrates Cry for Help' The [Melbourne]Age (2 April 2018) online: The Age $<$ https://www.theage.com.au/national/victoria/struggling-magistrates-cry-forhelp-20180401-p4z7bh.html>; Peter Wilmoth, 'Loneliness, panic attacks, insomnia: Life for some on the judicial bench' The Sydney Morning Herald (2 August 2018) online: SMH $<$ https://www.smh.com.au/national/loneliness-panic-attacks-insomnia-life-for-some-on-the-judicialbench-20180731-p4zukq.html>.

${ }^{9}$ Skip Simpson and Paul Quinnett, 'Preventing Suicide: A Challenge to the Legal Profession' (2008) GP Solo 60, 60 .

${ }^{10}$ Seligman et al, above n5, 49-50. 
University found that even adjusting for socio-demographic factors, the legal profession suffered from major depressive disorders at 3.6 times the rate of other workers. ${ }^{11}$

In 2009, Australia's Brain and Mind Research Institute (BMRI) conducted research into depression, distress and other mental illnesses in lawyers and law students. ${ }^{12}$ Its report confirmed what had already been found in the United States (US) and Canada; that law students are at high risk of depression and psychological distress. Indeed, the BMRI found that 35 per cent of law students reported high levels of distress as compared to 13 per cent of the general community.

It seems then that both attending law school and practising law are health hazards. ${ }^{13}$ And since law is such a public profession, dysfunction within it can entail '.... societal, as well as personal, costs. Indeed, the creation of law itself is in one sense bound up with the health of judges, lawyers, legislators, and academics. ${ }^{14}$

As Thornton observes though, it is difficult to temper the psychological distress of law students (or lawyers) where it emanates from unknown causes. ${ }^{15}$ Therefore, gaining a

\footnotetext{
11 Ibid, 53.

${ }^{12}$ Kelk et al, above n3, 46; Margaret Thornton, 'Law student wellbeing: A neoliberal conundrum' (2016) 58(2) Australian Universities Review 42, 42.

${ }^{13}$ Penrose, above n4, 8 .

${ }^{14}$ Martin E. P. Seligman, Paul R.Verkuil, and Terry H. Kang 'Why lawyers are unhappy' (2005) 10(1) Deakin Law Review 49, 50-51.

15 Thornton, above n12, 42.
} 
better understanding of the factors that contribute to this dysfunction in both populations with a view to identifying possible remedies (or better still, prevention) is a worthwhile exercise.

\section{Why Such High Rates of Mental Illness?}

A number of possible explanations have been proposed to account for the high levels of mental illness and distress within both the legal profession and in law students. These explanations canvas and cross the boundaries of individual, psychological, organizational, cultural and societal perspectives. Factors contributing to high levels of psychological distress may, for example, include the individual personality profiles of law students and legal practitioners, ${ }^{16}$ the work culture of the legal profession, ${ }^{17}$ workplace bullying and harassment, ${ }^{18}$ high work caseloads (especially for judges and

\footnotetext{
${ }^{16}$ Penrose, above n4, 58.

${ }^{17}$ Chan, above n4, 58 .

${ }^{18}$ Sophie Schroder, 'Lawyers some of Australia's worst bullies?' Australasian Lawyer (8 October 2014) online: Australasian Lawyer<https://www.australasianlawyer.com.au/news/lawyers-some-ofaustralias-worst-bullies-192671.aspx>. See also, the International Bar Association report, Us Too? Bullying and sexual harassment in the Legal Profession (IBA, 2019).
} 
magistrates), under-resourcing, ${ }^{19}$ low levels of autonomy and decision latitude ${ }^{20}$ the adversarial nature of the legal practice (particularly in common law countries and jurisdictions) ${ }^{21}$ social trends such as neoliberalism, ${ }^{22}$ increased levels of (often critical, uninformed, and biased) public scrutiny from the media and politicians, and in the case of judicial officers especially, the solitary and independent nature of their work. ${ }^{23}$ Additionally, relentless public criticism for being "soft on crime", "tough" or accusatory language around so-called "errors" in judicial decision-making levelled by superior courts in appeal decisions, and the need for judicial officers to advocate on behalf of unrepresented litigants in the context of reduced legal aid funding can all take their toll and have potentially devastating impacts on the psychological well-

\footnotetext{
${ }^{19}$ Recent figures suggest that in the Australian State of Victoria, 120 magistrates and court registrars heard more than 680,000 criminal matters in the 2015-16 financial year and could face a daily load of 50 cases on matters ranging from family violence and assault to driving offences: Peter Wilmoth, 'Loneliness, panic attacks, insomnia: Life for some on the judicial bench' The Sydney Morning Herald (2 August 2018) online: SMH < https://www.smh.com.au/national/loneliness-panic-attacks-insomnia-life-forsome-on-the-judicial-bench-20180731-p4zukq.html; Each magistrate in Victoria oversees an average 8000 hearings [2500 cases] annually, while half the cases in the County Court are sexual offences, often involving children: Adam Cooper, 'What you don't understand about our job: judges, magistrates speak out' The ([Melbourne]Age (3 August 2018) online: The Age $<$ https://www.theage.com.au/national/victoria/what-you-don-t-understand-about-our-job-judges-magistratesspeak-out-20180803-p4zvey.html>.

${ }^{20}$ Seligman et al, above n5, 50 .

${ }^{21}$ Judy Gutman 'Litigation as a Measure of Last Resort: Opportunities and Challenges for Legal Practitioners with the Rise of ADR' (2015) 14(1) Legal Ethics 1-21.

22 Thornton, above n12, 42-49.

${ }^{23}$ Adam Cooper, 'What you don't understand about our job: judges, magistrates speak out' The Age on-line 3 August $2018<$ https://www.theage.com.au/national/victoria/what-you-don-t-understand-about-ourjob-judges-magistrates-speak-out-20180803-p4zvey.html>; Peter Wilmoth, 'Loneliness, panic attacks, insomnia: Life for some on the judicial bench' The Sydney Morning Herald on-line 2 August 2018 $<$ https://www.smh.com.au/national/loneliness-panic-attacks-insomnia-life-for-some-on-the-judicial-bench20180731-p4zukq.html>.
} 
being of practitioners. ${ }^{24}$ These possible explanations for high levels of mental illness in the legal profession are further explored below. As Jenaway points out though, compounding all of the above is of course the unfavourable public perception of lawyers - supported by a plethora of movies and jokes - as immoral, ruthless mercenaries.' 25

\section{A. Mental Health Within the Legal Profession}

The nature of the work undertaken by lawyers, including being exposed to vicarious trauma, constant work pressures including hefty caseloads and substantial (and potentially unachievable) 'billable hours' targets, ${ }^{26}$ a lack of workplace flexibility and poor workplace cultures can all add to or cause psychological distress among legal practitioners. ${ }^{27}$ Where there is a working environment which may necessarily

'[C]ombine [the loneliness of solitary, independent decision-making and] dealing with a really vile and traumatic case involving shocking child pornography and then going

\footnotetext{
${ }^{24}$ Peter Wilmoth, 'Loneliness, panic attacks, insomnia: Life for some on the judicial bench' The Sydney Morning Herald on-line 2 August $2018<$ https://www.smh.com.au/national/loneliness-panicattacks-insomnia-life-for-some-on-the-judicial-bench-20180731-p4zukq.html>.

${ }^{25}$ Gutman above n21, 8 .

${ }^{26}$ See for example Yale Law School, The Truth about the Billable Hour (updated July 2017) online: Yale Law School <https://law.yale.edu/truth-about-billable-hour-0ome private law firms> where billing 37.5 hours per week (the average Australian working-week) requires lawyers to spend long hours at work to achieve revenue targets.

${ }^{27}$ Kelk et al, above n3; and Chan above n4, 58 .
} 
home to your kids or grandkids and trying to put that out of your mind and you've been alone all day making decisions. That's a challenge. ${ }^{28}$

In addition, Australia's legal professional culture generally tends to be 'maledominated, money-centred, overly competitive (thus encouraging aggression rather than collaboration)' with unreasonable expectations around working hours. ${ }^{29}$ These characteristics are not inherently conducive to achieving good mental health and wellbeing or work-life balance. There is also evidence that the levels of adversarialism inherent in the nature of legal practice in common law jurisdictions:

'.... negatively impacts on the social well-being and mental health of legal
practitioners... [and that] ... [d]ecreased adversarialism may lead to a happier and
healthier legal profession, which [would necessarily benefit] the administration of
justice.'

Further complicating a complex and difficult picture - an environment in which overwork and under-resourcing is rife, in which a commitment to social justice is not always translatable into day-to-day basis work practices, and in which practitioners are apparently reluctant to admit to, report, or seek help with their psychological struggles - is the fact that almost a third of legal professional disciplinary matters

\footnotetext{
${ }^{28}$ Victorian County Court Chief Judge Peter Kidd: Adam Cooper, 'What you don't understand about our job: judges, magistrates speak out' The Age on-line 3 August 2018

$<\underline{\text { https://www.theage.com.au/national/victoria/what-you-don-t-understand-about-our-job-judges-magistrates- }}$ speak-out-20180803-p4zvey.html>.

${ }^{29}$ Chan, above n4, 58.

${ }^{30}$ Gutman, above n 21, 2.
} 
involve issues of lawyer mental ill-health. ${ }^{31}$ In other words, severely impaired professional practice can be a consequence of poor mental health, and may in fact be the issue that first brings the practitioner's mental disorder to light. ${ }^{32}$ This is a vicious circle in which compromised mental health leads to poor professional performance, judgement and misconduct, the consequences of which in turn, exacerbate poor mental health and distress.

\section{B. The Mental Health of Australian Law Students}

While some students may self-select to study law because of the status associated with having a law degree, ${ }^{33}$ research also suggests that certain personality traits such as competitive behaviour, ${ }^{34}$ high achievement-orientation, ${ }^{35}$ and pessimistic tendencies also predispose law students to a risk of depression when they become lawyers. ${ }^{36}$ Additionally, law schools may act as potential breeding grounds for future lawyer demoralization. ${ }^{37}$ Legal education is said to promote certain types of behaviours such

\footnotetext{
${ }^{31}$ Penrose, above n6, 10.

32 This figure is based on an estimate by John Briton, the Queensland Legal Services Commissioner, but it is likely that this would be reflected in other Australian States and Territories: Penrose, above n6, 10 .

${ }^{33}$ Wendy Larcombe, Ian Malkin and Pip Nicholson, 'Law Students' Motivations, Expectations and levels of Psychological Distress: Evidence and Connections' (2012) 22 Legal Education Review 71, 89.

${ }^{34}$ Ivar Nordmo and Akylina Samara, 'The Study Experience of the High Achievers in a Competitive Academic Environment: A Cost of Success?' (2009) Issues in Educational Research 255.

${ }^{35}$ Gerald Hess, 'Heads and Hearts: The Teaching and Learning Environment in Law School' (2002) 52 Journal of Legal Education 75.

36 Seligman et al, above n5, 52-54.

${ }^{37}$ Ibid.
} 
as being defensive, pessimistic and perfectionist - in law students these behaviours may, in turn, lead to unhappiness. ${ }^{38}$

Australian and other research has found that law students do not demonstrate elevated psychological distress before law school - distress only manifests during the first year of university study. ${ }^{39}$ Still, 'pessimism' is not inherently pejorative - it may be reframed as 'prudence' - a healthy caution, scepticism and 'reality-appreciation' which may be a professional (if not personal) asset for law students and lawyers. ${ }^{40}$ It is a quality embraced both in legal education ${ }^{41}$ and by the legal profession because it enables 'good lawyers' to see the 'snares and catastrophes that might conceivably occur in any given transaction' ${ }^{42}$ While this ability may well benefit the client, it is not always beneficial for lawyers within their private spheres. ${ }^{43}$ Educating law students to display the qualities of 'detachment, adversarialism and neutrality' or to 'think like a lawyer' may negatively impact on student well-being. ${ }^{44}$ This points to the need to

\footnotetext{
${ }^{38}$ Susan Daicoff, ‘Lawyer, Know Thyself’ (1997) 46(5) American University Law Review 1337.

${ }^{39}$ Thornton, above n12, 43; Kennon M Sheldon and Lawrence S Krieger, 'Does Legal Education Have Undermining Effects on Law Students? Evaluating Changes in Motivation, Values and Well Being' (2004) 22 Behavioural Sciences and the Law 262, 275; Molly Townes O'Brien, Stephen Tang and Kath Hall, 'Changing Our Thinking Empirical Research on Law Student Wellbeing, Thinking Styles and the Law Curriculum' (2011) 21 Legal Education Review 149.

${ }^{40}$ Seligman et al above n5, 56 .

${ }^{41}$ Ibid.

${ }^{42}$ Ibid.

${ }^{43}$ Ibid, 49.

${ }^{44}$ Thornton, above n12, 52.
} 
develop skills to recognise the difference between the psychological attitudes and approaches needed at work versus those required at play. ${ }^{45}$

A number of studies have confirmed that Australian law students experience high to very high levels of psychological distress in comparison to other people in the community. ${ }^{46}$ For instance study by Leahy et al found that law student psychological distress levels (58 per cent) were higher than those of mechanical engineering students (50 per cent), medical students (44 per cent) and psychology students (40 per cent). ${ }^{47}$ While (South) Australia's tertiary students generally are four times more likely to be psychologically distressed than their age-matched peers from the general population. ${ }^{48}$ A further study that compared law and psychology students again found that law students had higher mean anxiety and depressive scores. ${ }^{49}$

That said, other research indicates that law students as a group do not necessarily experience more psychological distress than non-law students and that distress is a

\footnotetext{
${ }^{45}$ Seligman et al above n5.

${ }^{46}$ Kelk et al, above n 3 .

${ }^{47}$ Catherine M. Leahy, Ray F. Peterson, Ian G. Wilson, Jonathan W. Newbury, Anne L. Tonkin, Deborah Turnbull, 'Distress levels and self-reported treatment rates for medicine, law, psychology and mechanical engineering tertiary students: cross-sectional study' (2010) Australian and New Zealand Journal of Psychiatry 608 at 609.

${ }^{48} \mathrm{Ibid}, 609,613$.

${ }^{49}$ Natalie Skead and Shane Rogers, 'Do Law Students Stand Apart From Other University Students in their Quest for Mental Health: A Comparative Study on Wellbeing and Associated Behaviours in Law and Psychology Students', (2015) International Journal of Law and Psychiatry 42-43, 81-90.
} 
university student-wide problem..$^{50}$ For instance, Larcombe et al found that veterinary science students at the University of Melbourne experienced higher levels of psychological distress than law students, ${ }^{51}$ although law students recorded higher levels of stress than disciplines such as engineering and science. ${ }^{52}$

The culture of legal education itself has attracted research attention with much of the early work on the mental health of students undertaken in the US. A longitudinal study led by Benjamin found that symptoms of psychological distress in law students increased significantly in the first year of law and persisted throughout their degree studies, to post-graduation, ${ }^{53}$ having a negative effect on their overall mental health. ${ }^{54}$ Recent Australian research mirrors these findings. For example, $\mathrm{O}^{\prime}$ Brien et al found that prior to entering law school, law students have similar levels of wellbeing to, and in some cases higher levels, than those reported in the general population. ${ }^{55}$ However, from the first semester in law school, law students begin to experience stress, anxiety and depression at rates higher than students in other disciplines such as medicine,

\footnotetext{
${ }^{50}$ Wendy Larcombe, Sue Fince and Rachel Sore, ‘Who's Distressed? Not Only Law Students: Psychological Distress Levels in University Students Across Diverse Fields of Study (2015) 37 Sydney Law Review 243.

${ }^{51}$ Ibid.

${ }^{52}$ Ibid.

${ }^{53}$ Andrew Benjamin, Alfred Kaszniak, Bruce Sales and Stephen Shanfield, 'The Role of Legal Education in Producing Psychological Distress Among Law Students and Lawyers' (1986) 11 American Bar Foundation Research Journal 2.

${ }^{54}$ Ibid.

${ }^{55} \mathrm{O}$ 'Brien et al, above n39, 149.
} 
psychology and engineering. ${ }^{56}$ Further, a study conducted by Lester et al reported a significant increase in symptoms of depression in law students from the beginning to the end of first year. ${ }^{57}$ Lester's study showed that by the end of first year of law school, 15 per cent of students reported symptoms indicating moderate to very high levels of depression requiring possible clinical investigation as compared to 8.5 per cent at the beginning of first year. ${ }^{58}$

This then leads to further questions about curriculum design and its potential contribution to the psychological distress of law students. ${ }^{59}$ For example, does an emphasis on rational legal reasoning and linear thinking (which may be disconnected from social justice issues and de-emphasise creativity, personal values and reflection), ${ }^{60}$ together with teaching practices such as the Socratic method, ${ }^{61}$ have a negative impact on law student health and well-being? And does the learning environment within law schools - with its typically highly competitive nature and

\footnotetext{
${ }^{56}$ Ibid.

${ }^{57}$ Anthony Lester, Lloyd England and Natalia Antolak-Saper 'Health and Wellbeing in the First Year: The Law School Experience' (2011) 36 (1) Alternative Law Journal 47.

${ }^{58}$ Ibid.

${ }^{59} \mathrm{O}^{\prime}$ Brien et al, above n39, 149.

${ }^{59}$ Ibid.

${ }^{60}$ James Duffy, Rachael Field and Melinda Shirley, 'Engaging Law Students to Promote Psychological Health' (2011) Alternative Law Journal 250; Anne Colby, Judith Welch Wegner, Lee Shulman, Lloyd Bond, and William M. Sullivan, Educating Lawyers: Preparation for the Profession of Law, Jossey Bass, 2007; Jean Stefancic and Ricard Delgado, How Lawyers Lose their Way: A Profession Fails its Creative Minds, Duke University Press, 2005.

${ }^{61}$ Anna Huggins, 'Autonomy Supportive Curriculum Design: A Salient Factor is Promoting Law Students Wellbeing (2012), University of New South Wales Law Journal 683.
} 
heavy workloads also contribute to reduced levels of law student well-being? ${ }^{62}$ Do they, in turn, reduce student peer support, ${ }^{63}$ as well as opportunities for it to occur? Other contributing factors may include inadequate feedback, a lack of competence and autonomy, ${ }^{64}$ a lack of social connectedness, ${ }^{65}$ and inadequate support of services for students. ${ }^{66}$ Extrinsic factors such as why students wanted to study law in the first place, ${ }^{67}$ and the rewards for doing so, as well as a preoccupation with academic results and ranking, ${ }^{68}$ may also have a part to play.

Researchers have also considered the socio-economic context of law students to assess whether these factors are also contribute to psychological distress. Those studies highlight that factors such as age, ${ }^{69}$ gender, ${ }^{70}$ employment (including the number of

\footnotetext{
${ }^{62}$ Ibid.

${ }^{63}$ Vozzo, above n4, 10 and Kelk et al, above n3, 46.

${ }^{64}$ Huggins, above n61, 683.

${ }^{65}$ Natalie Skead and Shane L Rogers, 'Stress, Anxiety and Depression in Law Students: How Student
} Behaviours Affect Student Wellbeing', (2014) Monash Law Review 40, 2. The authors conclude that social connectedness is central to wellbeing of law students.

${ }^{66}$ Huggins, above n61, 683.

${ }^{67}$ Dominic Fitzsimmons, Simon Kozlina and Prue Vines, 'Optimising the First Year Experience in Law: The Law Peer Tutor Program at the University.

${ }^{68}$ Wendy Larcombe, Ian Malkin and Pip Nicholson, 'Law Students' Motivations Expectations and Levels of Psychological Distress: Evidence and Connections (2012), 22 Legal Education Review, 71, 85, 86.

${ }^{69}$ Wendy Larcombe, Sue Finch, Rachel Sore, Christina M. Murray, Sandra Kentish, Raoul A. Mulder, Parshia Lee-Stecum, Chi Baik, Orania Tokatlidis \& David A. Williams ‘Prevalence and SocioDemographic Correlates of Psychological Distress Among Students at an Australian University (2016) Studies in Higher Education, 41:6, 1074-1091.

${ }^{70}$ Wendy Larcombe, Letty Tumbaga, Ian Malkin, Pip Nicolson, Orania Tokatlidis, 'Does and Improved Experience of Law School Protect Students from Depression, Anxiety and Stress? An Empirical Study of 1 and the Law School Experience of LLB and JD Students' (2012) University of 
hours worked), ${ }^{71}$ and caring responsibilities ${ }^{72}$ may all influence the psychological distress of law students.

Soh et al found that law students had not acquired a foundational level of mental literacy to ensure their own wellbeing. Further, this study found that while many law students suffered from high to very high levels of stress, they also lacked a proactive approach to seek out medical and health services, ${ }^{73}$ raising questions about why this would be so in an otherwise intelligent and (at least initially, pre-law school) welladjusted cohort of students.

It seems then that the high levels of psychological distress among law students is a multi-factorial problem - and actually going to law school is (or becomes) part of that problem. But it is also important to consider the broader socio-economic context ${ }^{74}$ as

Melbourne Law Research Services,1; Nerissa Soh, Fiona Burns, Rita Shackel, Bruce Robinson and Michael Robertson, 'Law Student Mental Health Literacy and Distress: Finances, Accommodation and Travel Time, (2015) Legal Education Review 251.

${ }^{71}$ Helen Stallman 'Psychological Distress in University Students: A Comparison with General Population Data' (2011) Australian Psychologist 45, 4.

${ }^{72}$ Wendy Larcombe and Katherine Fethers, 'Schooling the Blues? An Investigation of Factors Associated with Psychological Distress Among Law Students, (2013) University of New South Wales Law Journal 390.

73 Ibid.

${ }^{74}$ Larcombe et al, above n72. More importantly the study shows that you need to take care before making broad assumptions in relation to the reasons behind law students' high psychological distress levels. 
well as students' own personality traits, characteristics, expectations and motivations. ${ }^{75}$

Some researchers have criticised the conclusions drawn from empirical research and argued that looking at the law school experience (including the "legal thinking" taught there) misses the "wider picture". Parker, for example, claims that mental distress is a society-wide problem which cannot be treated at an individual level. ${ }^{76}$

However, as Thornton points out, the growing body of Australian literature around law student well-being which emerged in the $21^{\text {st }}$ century offers no explanation for the sudden 'eruption of psychological distresses among law students' ${ }^{77}$ Leahy et al did not attempt to explain why tertiary student distress rates are significantly higher than age-matched peers who were not tertiary students but did suggest that changing university cultures may well be a factor. ${ }^{78}$ Additionally, the many competing demands faced by students including part-time work, intensive discipline-based academic commitments (common to disciplines such as medicine, law and mechanical engineering) and family obligations are likely to play a role. ${ }^{79}$ They postulated that

\footnotetext{
${ }^{75}$ Larcombe et al, above n72, 85-86.

${ }^{76}$ Christine Parker, 'The "Moral Panic" Over Psychological Wellbeing in the Legal Profession: A Personal or Political Ethical Response?' (2014) 37 UNSW Law Journal 1103, 1121.

77 Thornton, above n12, 42.

${ }^{78}$ Leahy et al, above n47, 608-609.

${ }^{79}$ Ibid.
} 
since these multi-factorial demands minimize time for social activities and relaxation, they could contribute to the high rates of reported psychological distress. ${ }^{80}$

In Thornton's view though, the focus on law student well-being individualises and depoliticises the problem, shifting focus from the significant role played by the neoliberalism of Australia's higher education and transforming it from a public to a private good. In her view, the ways in which law students are taught - the "how" and the "what" of legal education - could be altered to ensure they are better equipped to deal with the pressures of the "age" ${ }^{81}$ Specifically she argues that law schools should be more transparent about labour market problems and the curriculum 'diversified to prepare students for a range of employment destinations other than traditional legal practice' ${ }^{82}$ This does not deflect from the fact that law students are suffering distress, that many of them will enter legal practice after their studies, and that their future selves are likely to experience the same levels of psychological distress as contemporary lawyers do. Unless of course, some action is taken to change either their capacity to cope or the legal culture in which they find themselves.

Australia's tertiary sector has long been concerned with the high prevalence of mental health problems in all university students, not just law students, as this cohort has

\footnotetext{
${ }^{80}$ Ibid.

${ }^{81}$ Thornton, above n12, 42.

${ }^{82}$ Ibid.
} 
been identified as being an at-risk population. ${ }^{83}$ Stallman argues that this highlights the need for universal "early interventions" to prevent the development of severe mental illness in university students and that it is an issue that should be of concern for all educators. ${ }^{84}$

\section{Law: Australian mental health Initiatives}

Over the last decade, in line with an increased community awareness of the high levels of mental health issues and distress experienced by the legal profession and law students, $^{85}$ a number of mental health and wellbeing initiatives have been implemented by the legal profession and the academy. ${ }^{86}$

There has also been broader support for initiatives that look at cultural, organisational and societal issues to support the legal profession and law students. In 2012, Fisher identified a number of initiatives to make life in legal organizations, universities, law firms and the courts 'less stressful and more supportive for legal practitioners and students'. These included providing education about mental illness (including triggers, preventative measures and effective remedies), addressing toxic workplace cultures, emphasising the role of 'enlightened leadership' (including by putting

\footnotetext{
${ }^{83}$ Stallman, above $n 71,4$.

${ }^{84}$ Ibid.

${ }^{85}$ Briana Everett, Perils the profession can't ignore (12 December 2011) Lawyers Weekly http://www.lawyersweekly.com.au/news/repairing-the-paradox and BMRI Report. Janet Chan 'Depression, Anxiety \& Stress in the Legal Profession', Law Institute of Victoria Journal December 2014 ${ }^{86}$ Helm, above n2, 6 .
} 
meaningful, confidential and accessible pastoral care systems in place), and examining ways to increase individual and team resilience in the face of work stress. ${ }^{87}$

A. Initiatives within the legal/judicial profession

By 2014 Australia's legal professional associations had generally accepted that lawyer mental wellbeing was an industry and profession-wide issue requiring action. ${ }^{88}$ Prior to this though the profession had already been quietly taking steps to address these concerns. ${ }^{89}$

The peak representative body of the Australian legal profession, the Law Council of Australia, provides a national support mechanism through its mental health and wellbeing portal. ${ }^{90}$ Further, the law societies/institutes of each Australian State and Territory seek to raise awareness of and to remove the stigma of mental illness in the

\footnotetext{
${ }^{87}$ Penrose, above n6, 9.

${ }^{88}$ Helm, above n2, 6.

${ }^{89}$ Beyond Blue and Beaton Consulting, the National Depression Initiative Report 2007; online: https://www.beyondblue.org.au/media/media-releases/media-releases/professionals-unsure-of-how-to-managedepression-and-anxiety-disorders-in-the-workplace. Overall the survey found that professionals and students experience more symptoms of depression than the rest of the population, and that the symptoms of depression amongst lawyers and law students, when compared to other professions were high.

${ }^{90}$ Law Council of Australia, online: https://www.lawcouncil.asn.au/policy-agenda/advancing-theprofession/mental-health-and-wellbeing-in-the-legal-profession.
} 
legal profession and in law students. They also provide a range of services to support mental health and wellbeing of their member lawyers. ${ }^{91}$

Along with raising awareness of the mental health issues impacting on members of the legal profession, it has become easier for members of the profession to access mental health services. ${ }^{92}$ Together, these factors have all contributed to a growing national conversation about the mental health and wellbeing of the legal profession, ${ }^{93}$ much of which has focused on the structural factors leading to poor mental health within the profession. ${ }^{94} \mathrm{~A}$ recent inquiry by Victoria's workplace health and safety regulator, Worksafe, into employee fatigue at one of Australia's "top-tier" law firm, for example, highlighted mental health issues and safety risks in legal workplaces. ${ }^{95}$ Worksafe's inquiry arose in the context of a complaint to the Royal Commission into

\footnotetext{
${ }^{91}$ Each Law Society has a range of services that includes access to counselling services for their members and families and continuing legal education to improve mental health and wellbeing of the legal profession.

${ }^{92}$ For example, the Victorian Bar has a 24-hour counselling service; many large firms and government agencies have employee assistance programs (EAP) _ which provide confidential counselling services.

${ }^{93}$ Those forums include, but aren't limited to: the National Wellness for Law which explores issues of mental health and wellbeing in the legal profession and law students through the exchange from the profession, academia and its supporters and the Australian Wellness Network for Law that provides hub for sharing of information and resources - a community of legal academics, practitioners and students who are committed to: first, addressing the high levels of psychological distress experienced in law; and second, promoting wellness at law school, in the legal academy, and in the profession.

${ }^{94}$ Jennifer Windsor, Maria Nawaz Submission to the Productivity Commission Inquiry into Mental Health (Law Society of New South Wales Young Lawyers, 19 April 2019) 9, available on-line at https://www.pc.gov.au/_data/assets/pdf_file/0012/241203/sub456-mental-health.pdf.

${ }^{95} \mathrm{Ibid}$, at 3.
} 
Misconduct in the Banking and Finance Services Industry about overwork in the profession. ${ }^{96}$

In relation to this complaint, Thompson et al reported on 12 October 2018:

'graduates were subject to gruelling conditions, with some employees choosing to sleep at the firm's Melbourne office rather than return home. Day and night shifts were allocated, so work could continue around the clock'.97

In a follow-up article in the Australian Financial Review on 26 October 2018, Whyte et al suggested that the problems of overwork and fatigue in the legal profession extended to the particular law firm mentioned in the WorkSafe complaint. ${ }^{98}$

Yet, at the same time, a number of law firms have taken initiatives to assist their staff with mental health and wellbeing issues, including by employing an on-site psychologist to provide early intervention to assist staff with any mental health and well-being issues. ${ }^{99}$

\footnotetext{
${ }^{96}$ Ibid, at 9.

${ }^{97}$ Ibid. see also Sarah Thompson, Jemima Whyte and David Marin-Guzman, 'King \& Wood Mallesons Investigated for Overworking Employees' (The Australian Financial Review, 12 October 2019) online: https://www.afr.com/companies/king--wood-mallesons-investigated-for-overworking-employees20181011-h16hei; Kate Allman 'The Burnout Profession' (Law Society Journal 27 March 2019) online: https://lsj.com.au/articles/the-burnout-profession/.

98 Jemima Whyte 'Worksafe Investigation Lifts Lid On Can of Worms' (Australian Financial Review (26 October 2018)

${ }^{99}$ Hannah Wooton 'Law firm brings psychologist on site as mental health wanes' (Australian Financial Review 31 October 2019) 6 online: https:/www.afr.com/companies/professionalservices/law-firm-brings-psychologist-on-site-as-mental-health-wanes-20191023-p533g6.
} 
Perhaps more importantly, there has been a generational change occurring in how millennials approach the nature of work. For example, Furlong argues that we are at an important transition in the evolution of legal services with a new generation of lawyers demanding a better work-life balance. ${ }^{100}$ Furlong argues that the next generation of lawyers will 'rewrite he DNA of law firms'101 and reshape the legal industry, ${ }^{102}$ as millennials take-over the legal industry. ${ }^{103}$

\section{B. Initiatives within the Australian Academy}

Since the BMRI report, law schools across Australia have implemented a range of strategies to address law student mental health well-being with strategies varying depending upon the particular social and cultural setting of the university. Law school budgets, funding for mental health initiatives, leadership commitment, student

\footnotetext{
${ }^{100}$ Jordan Furlong, 'The rise of the millennial lawyer' Lawyers on Demand Report (24 May 2017) online: <https://www.lodlaw.com/reports/rise-millenial-lawyer>. This new generation of lawyer also wants collaboration, connection and diversity of work.

${ }^{101} \mathrm{Ibid}$. See also Doris Bozin, Allison Ballard and Vicki de Prazer, 'Interdisciplinary Collaboration to Benefit 'New' and Emerging Lawyers' in Judith Marychurch and Adiva Sifris, Wellness for Law: Making Wellness Core Business' (LexisNexis Butterworths, Australia, 2019) 229-238.

102 Margot Freedman Alicks 'How millennials are reshaping the practice of law' (Colorado Biz 19 November 2018) online: https://www.cobizmag.com/Trends/How-Millennials-are-Reshaping-thePractice-of-Law/..

${ }^{103}$ Amanda Robert, 'Millennials are poised to take over; how will the legal industry need to change?' (American Bar Association Journal 1 March 2019) online: $<$ http://www.abajournal.com/news/article/millennials-are-a-dominant-force..
} 
communities, and law course mode of delivery are all important factors in determining the types of strategies that a given law school adopts. ${ }^{104}$

Australian legal academics acknowledge the importance of addressing the issue of high levels of law student psychological distress in a range of different ways. ${ }^{105}$ Many working within this community feel they have a responsibility to ameliorate the high levels of distress experienced by students, believing it to be an ethical responsibility of academics. ${ }^{106}$ In 2009 though Hall noted that some academics (and students) were blinded by certain cognitive barriers that obstructed their understanding of research on psychological wellbeing in law school. ${ }^{107}$ and that Australian law schools needed to take steps to 'avoid the unintentional denial and rationalisation that can occur around issues of student wellbeing' 108 and to 'consider how to create environments where both academic staff and students are encouraged to reflect on the impact of legal education on their own thinking and emotional wellbeing. ${ }^{109}$ As Hall observed 'a spectrum of respected sources tell us that high levels of emotional health, maturity

\footnotetext{
${ }^{104}$ BMRI Report, 48

${ }^{105}$ Rachel Field and James Duffy, 'Better to Light a Single Candle than Curse the Darkness: Promoting Law Student Well-Being through a First Year Law Subject', (2012) 12 QUL Law and Justice Journal 1.

106 Rachel Field, ALTC Fellowship Flinders Presentation, 17 September 2013, online: http://www.google.com/url?sa=t\&rct=j\&q=\&esrc=s\&source=web\&cd=1\&ved=2ahUKEwjq8LLa783eAhXWbn 0KHbPiCaYQFjAAegQIBRAC\&url=http\%3A\%2F\%2Fwww.flinders.edu.au\%2FTeaching_and_Learning_File s\%2FDocuments\%2FALTC_Fellowship\%2520Flinders\%2520Presentation_17\%2520September\%25202013.pp t\&usg=AOvVaw2_RIZYBLb7-P8a6oummy6e.

${ }^{107}$ Kath Hall, 'Do We Really Want to Know? Recognising the Importance of Student Psychological Wellbeing in Australian Law Schools, (2009) 9(1) QUT Law Journal 4.

108 Ibid, 11.

109 Ibid, 12.
} 
and life satisfaction come from understanding and expressing our values, commitments and character.' ${ }^{\prime 10}$

Initiatives such as the Council and Law Deans of Australia's support and funding of good practice well-being guidelines provide valuable resources for law schools. ${ }^{111}$ So too does the development of a set of graduate attributes (the competencies, skills and knowledge of law that relate personal behaviour to professional practice), ${ }^{112}$ and initiatives to assist the transition to university and to help reduce law student psychological distress while at university. Most of the work involves rethinking how the law curriculum is delivered, teaching strategies and the culture of law schools, ${ }^{113}$ and part of that process has been to develop support mechanisms that are especially related to resilience and changing the legal learning culture. ${ }^{114}$

\footnotetext{
${ }^{110}$ Ibid.

111 The Australian Council of Law Deans ‘Promoting Law Student Well-Being Good Practice Guidelines for Law Schools, Revised (2014), online: https://cald.asn.au/resources.

112 The Council of Law Deans reference national and international statements on competencies, skills and knowledge of law graduates and the descriptors located in the Australian Qualification Framework for Bachelor Degree. An example includes the Threshold Learning Outcome 6: SelfManagement.

${ }^{113}$ Field et al, above n105, 133; Penelope Watson and Rachel Field 'Promoting Well-Being and Resilience at Law School' in Sally Kift et al (eds), Excellence and Innovation in Legal Education (LexisNexis, 2011).

${ }^{114}$ Rachel Field and Sally Kift, 'Addressing the High Levels of Psychological Distress in Law Students Through Intentional Assessment and Feedback Design in First Year Law Curriculum' (2010 1 The International Journal of First Year in Higher Education 65, 67.
} 
Law schools have also focused on a range of initiatives to deal with mental health and well-being of students. ${ }^{115}$ Those initiatives essentially fall into three categories: a whole of law school approach; a focus on law school culture; and a focus on these issues within a specific course/unit of law degree studies. Some approaches combine all three initiatives.

As will be seen below, within this framework the pilot health-justice project at the University of Canberra sought to utilise the latter: raising awareness about the importance of self-awareness and resilience as a skill, providing resilience-building strategies and providing support mechanisms through pastoral care, in the context of an academic unit which involved working in a health-justice legal clinic within the university environment.

Field argues that a whole of law school approach that looks structural systemic issues such as curriculum design, assessment and school culture is necessary. ${ }^{116}$ Both Field and Kift consider the strategic change needed in Australian legal education to properly address high level of 'psychological distress' of law students is particularly significant. ${ }^{117}$ They argue that intentionally designing the first-year curriculum design

\footnotetext{
${ }^{115}$ For a comprehensive list of the initiatives see Rachel Field and James Duffy above n 101. ${ }^{116}$ Ibid.

${ }^{117}$ Rachel Field, 'Promoting Law Student Well Being Through the Curriculum' Final Report of: Stimulating Strategic Change in Legal Education to Address High Levels of Psychological Distress in Law Students', ALTC Teaching Fellowship, 2014; Sally Kift, 'A Decade of Transition Pedagogy: A Quantum Leap in Conceptualizing the First Year Experience' 2 HERDSA Review of Higher Education (2015) 251.
} 
to address and prevent psychological distress in law students is critical. Firstly, they consider the problem of psychological distress in law students. Secondly, they explore a range of theoretical and practical strategies to assist the implementation of good assessment and feedback practice in the first year of legal education. ${ }^{118}$ They also consider that academic assessment and feedback practice during first year can be harnessed to assist students to successfully transition to studying law at university. ${ }^{119}$

Most law schools though tend to focus only on the first-year law student experience. They typically also develop transitional pedagogies with an integrated approach to student pastoral care to assist students to navigate their degrees, including through promoting student social connectedness. ${ }^{120}$ James Cook University (JCU) in Queensland adopted an approach directed towards alleviating psychological distress in first year law student program. JCU's approach incorporated a variety of student support strategies to scaffold student capacity for dealing with their academic and personal development. Strategies such as interactive teaching and learning settings, peer-assisted learning, regular email contact from first-year coordinators, an integrated approach to ancillary support services, and an effective mentor program

\footnotetext{
${ }^{118}$ Field et al, above n105, 65, 67.

${ }^{119}$ Ibid.

${ }^{120}$ Sally Kift, 'Articulating a Transition Pedagogy to Scaffold and to Enhance the First Year Student Learning Experience in Australian Higher Education: Final Report for ALTC Senior Fellowship Program' (August 2009) online: Australian Learning and Teaching Council, 16 $<$ http://www.altcexchange.edu.au/system/files/Kift\%2C_Sally_ALTC_Senior_Fellowship_Report_Sep _09.pdf>
} 
are all considered as integral to the success of JCU's first-year law program. Academics' own commitment to caring for students as individuals is also an essential ingredient in effective pastoral care. ${ }^{121}$ The approach effectively embeds pastoral care into the law curriculum. ${ }^{122}$

Developing (student) support programs that work alongside the law degree are also seen as a way to (positively) influence school culture. For instance, at the University of New South Wales (UNSW), the Law Peer Tutor Program was designed to assist first year law students successfully transition into law school. The program is funded by the law school and the learning centre and focuses on offering academic support and a social dimension. ${ }^{123}$ Monash University's Faculty of Law have designated 'University Student Experience Manager' roles and also provides a part-time psychologist to deal with students' specific concerns. Since 2009, mental health awareness, practical strategies designed to nurture resilience and coping behaviours incorporating neuroplasticity and mindfulness have also been included in the law school curriculum. ${ }^{124}$

\footnotetext{
${ }^{121}$ Kate Galloway, Rachel Bradshaw, Neil Dunbar and Jamie Fellows, 'Approaches to Student Support in the First Year of Law School' (2011) Legal Education Review 212.

${ }^{122}$ Ibid.

${ }^{123}$ Dominic Fitzsimmons, Simon Kozlina and Prue Vines, 'Optimising the first year experience in law: The law peer tutor program at the university' (2006) Legal Education Review 6.

${ }^{124}$ Lester et al, above $n 68,3$. The program includes a lecture delivered to first year law students at the beginning of the year. Part 1 of the Wellbeing and Law series, which discuss mental health and wellbeing and specific implications for students. At the end of the first year is Part 11 of the series: Performance@Law discussing students' performance in light of recent developments in
} 
Other examples of significant initiatives include offering specific units or a course of study within the law degree to assist law students. For example, within the administrative law unit at the Queensland University of Technology (QUT) law school, the content and assessment of the unit were modified to include an interdisciplinary approach. This approach included a psychologist providing psychological support to law students through raising awareness of mental wellbeing; coping mechanisms for studying law; improving student connections with peers, academics and psychological support services. As part of the psychological support provided, students were required to complete a resilience plan which emphasised stress and time management techniques. ${ }^{125}$

Yet despite these many initiatives there are still high levels of mental health issues amongst legal practitioners and law students. ${ }^{126}$ Larcombe et al found that even a "good" law school experience - small classes, strong class connectedness with first year lectures - may not correlate with lower stress. ${ }^{127}$ Larcombe's study indicated that overall satisfaction with a course designed to improve the students' experience of law

\footnotetext{
neuroplasticity - positive implications for learning, attention focus, attention density, resilience and graduate attributes are highlighted.

${ }^{125}$ Linda Crowley-Cyr, 'Promoting Mental Wellbeing of Law Students: Breaking Down Stigma \& Building Bridges with Support Services in the Online Learning Environment', (2014) QUT Law Review, 14, 1

${ }^{126}$ Sarah Whyte 'Tired, hungry and stressed out: What life is like for many Australian lawyers' ABC News 1 February 2018 https://www.abc.net.au/news/2018-02-01/stressed-lawyers-are-suffering-from-eatingdisorders:-study/9375696.

${ }^{127}$ Larcombe et al, above n72.
} 
school and enhance their academic engagement, may in fact have limited impact on their level of wellbeing. ${ }^{128}$

\section{The Role of Students, "Stigma", and Adaptation}

While many Australia law schools have invested significant resources in designing curricula and teaching programs that promote mental health in their law students, ${ }^{129}$ it is likely that the solution is not to be found entirely with law schools and academics. Arguably students must also take a degree of personal responsibility and consider what they can do for themselves to alleviate the stress, anxiety and depression that can result from attending law school. ${ }^{130}$

One underlying issue here may be that law students are reluctant to seek and obtain professional assistance when they experience negative stressors that impact on their mental health. ${ }^{131}$ This could result from the stigma ${ }^{132}$ attached to sharing the experiences or symptoms of "not coping", thereby increasing feelings of isolation and loneliness. ${ }^{133}$ Further, there may be a fear that in disclosing information the students may be singled-out - that is, that any (potentially adverse) information they disclose

\footnotetext{
128 Ibid.

${ }^{129}$ Field et al above n105, 1.

130 Skead et al, above 65, 42-43, 81-90.

${ }^{131}$ Crowley-Cyr see above n125.

${ }^{132}$ Ibid. A comprehensive definition of stigma at 134.

133 Although these studies relate to law students, it is not to say that it wouldn't apply to legal professionals; See also Seligman above n5.
} 
may be received and/or (mis)used by the university. ${ }^{134}$ For instance, they may (reasonably) be concerned about any impact of any such disclosure on their academic legal education, and their future admission to, and acceptance within the legal profession..$^{135}$

This stigma surrounding law students (and legal professionals) disclosing mental health issues, along with a lack of clarity surrounding the professional consequences also raises difficult questions for universities, regulatory bodies, future employees and employers. for law students, but also for legal professionals. ${ }^{136}$

The recent paradigm shift in understanding mental health in the general population is important here. ${ }^{137}$ Scientific work on understanding mental health has moved away from the factors and mechanisms that determine vulnerability to mental health, to factors and mechanisms that stimulate individuals to remain healthy or recover quickly when facing adversities over the course of their lives. ${ }^{138}$ Within this framework, resilience is considered an important component in individuals

\footnotetext{
${ }^{134}$ Crowley-Cyr see above n125.

${ }^{135}$ Ibid.

${ }^{136}$ Mary-Jane Ierodiaconou, Roberta Foster, 'Telling admissions: disclosing mental illness among lawyers' (Law Institute of Victoria Jan/Feb 2013 87 32) online: https://www.liv.asn.au/PracticeResources/Law-Institute-Journal/Archived-Issues/LII-Jan-Feb-2013/Telling-admissions--Disclosingmental-illness-amon>.

${ }^{137}$ Bart F Rutten, Caroline Hammels, Nicole Geschwind, Claudia Menne-Lothmann, Eshan Pishva, Koen Schruers, Daniel Louis van den Hove, Gunter Kenis, Marike Wichers, 'Resilience in mental health: linking psychological and neurobiological perspectives' (2013) Acta Psychiatrica Scandinavica $128,1$.

${ }^{138}$ Ibid.
} 
successfully adapting to adversity throughout their lives. ${ }^{139}$ Defining resilience is difficult, as there are different definitions and variable measurements which can preclude a proper analysis. ${ }^{140}$ The concept commonly incorporates the ability of an individual to recover from difficult experiences with minimal long-term adverse effects - in other words, the 'ability to bounce back or cope successfully despite substantial adversity.' ${ }^{141}$

In this context, the importance of law students and legal professionals being resilient is important and has been identified as an important legal skill. For example, a recent inquiry into the future of legal work recognised the importance of resilience, not just for the legal profession, but also for law graduates. ${ }^{142}$ The inquiry identified seven skills or areas of practice which were essential both for the future practice of law practice-ready graduate. Significantly, those skills included being resilient. ${ }^{143}$ It emphasised that resilience is a skill that can be learned, practiced and improved. ${ }^{144}$

\footnotetext{
${ }^{139}$ Ronald C Kessler, Katie A McLaughlin, Jennifer G Green, Michael Gruber, 'Childhood adversities and adult psychopathology in the WHO World Mental Health Surveys' (2010) The British Journal of Psychiatry 197, 5.

${ }^{140}$ Bart Rutten see above n137.

${ }^{141}$ Heidi Holtz, Katherine Heinze and Cynda Rushton 'Interprofessional' definition of moral resilience' (2017) Journal of Clinical Nursing 488 at 489.

${ }^{142}$ The Law Society of New South Wales, The Future of Law and Innovation in the Profession (2017).

${ }^{143}$ The Law Society of New South Wales, The Future of Law and Innovation in the Profession (2017). The other skills included: practice skills (interpersonal and professional); business skills; project management skills; internationalisation and cross border practice of law and inter-disciplinary skills.

${ }^{144}$ Paula Davis-Laack, Larry Richard and David Shearon, 'Four Things Resilient Lawyers Do Differently' Law Practice Today, 14 June 2016.
} 
While the practice of law has always been inherently stressful, changes to the profession and legal service delivery will expose the legal profession to extra layers of change and stress. ${ }^{145}$ Additionally, the advances in technology, economic pressures to revisit existing legal business models, and the globalisation of legal services, mean that the practice of law will be significantly different in the future to what it is now. ${ }^{146}$ This means that 'resilience' is not only important for the mental health and wellbeing of law students and lawyers, ${ }^{147}$ but also that it will also be necessary to cope with ongoing changes to the nature of legal work. ${ }^{148}$

In academia, one response to these challenges has been to 'build resilience, namely resources to sustain well-being in the face of adversity.'149 Many law schools acknowledging the link between mental health, wellness and resilience have students

${ }^{145}$ Ibid.

${ }^{146}$ Michael Legg, 'New skills for new lawyers: responding to technology and practice developments (1 January 2018). The Future of Australian Legal Education (Thomson Reuters 2018) UNSW Law Research No. 18-51.

${ }^{147}$ Speech delivered by Law Council President of Fiona McLeod 'Resilience and Resourcefulness Embracing Change, 10 August 2017, online https://www.lawcouncil.asn.au/media/speeches/resilience-andresourcefulness-embracing-change-and-opportunity?platform=hootsuite.

${ }^{148}$ Commission of Inquiry, 'Future of Law and Innovation in the Profession, (FLIP) Report (2017) The Law Society of NSW, online: https://www.lawsociety.com.au/sites/default/files/2018-03/1272952.pdf. European Commission, European Political Strategy, 'The Future of Work: Skills and Resilience for a World of Change' (2016) European Commission. The report doesn't specifically refer to legal work but focuses on the future of work and importance of resilience to the significant pace of change in the workplace.

${ }^{149}$ American Bar Association National Task Force on Lawyer Well-Being, The Path to Lawyer WellBeing. 
develop "resilience plans" and strategies to assist them in their academic studies and professional lives. ${ }^{150}$

Below we explore a health-justice clinic pilot program developed at the University of Canberra. The clinic was designed to improve student well-being and resilience through engaging students in an academic unit of study concurrent with the delivery of a legal service to clients while offering individual awareness-raising and pastoral care strategies. The clinic adopted an integrated approach as previously used by other law schools, ${ }^{151}$ but uniquely focused on developing student resilience and well-being by assessing individual characteristics and providing strategies in the context of a strong pastoral care program. It was significant too that the clinic was campus-based and located proximal to its health service partner. This on-site interdisciplinary program was offered within a unit available to LLB and JD students and was designed in collaboration with a general practitioner, psychologist, lawyers and legal academics.

\section{A Health-Justice Clinic Pilot Case Study}

Before exploring the UC pilot case study, a brief overview of the origins and history of health-justice partnerships, both internationally and in Australia.

\footnotetext{
${ }^{150}$ Crowley-Cyr see above n125.

${ }^{151}$ The Legal Advice Clinic unit has two clinical programs - Small Business Legal Advice Clinic and the Health Justice Legal Advice Clinic. The pilot program focussed on the latter clinic, because of the geographic proximity between the University of Canberra law school and the University of Canberra Medical and Counselling Service involved in the program.
} 


\section{A. Health-Justice Partnerships: A Brief Overview}

The first formal health-justice partnership (HJP) $)^{152}$ was established in the US in 1993 when Dr Barry Zuckerman, head of paediatrics at the Boston University School of Medicine, employed a lawyer to work with him to treat his patients. Zuckerman observed that he was repeatedly treating patients who lived in substandard housing and environments that caused significant and repeated health problems and sought legal assistance to address those poor living conditions and so prevent the ongoing health issues. ${ }^{153}$ The HJPs that followed similarly provided a mechanism for health and legal professionals to work together to address the legal and health-related needs of their mutual patients/clients. ${ }^{154}$ Such partnerships clearly offer significant benefits for the community, particularly where there is an intersection between the legal and 'social determinants of health' - which often relate to systemic factors outside a patient's control, including poverty, educational levels, unemployment and discrimination. ${ }^{155}$ In the context of a HJP, lawyers can often help remedy some of the problems causing health and others problems which may exacerbate health problems. Importantly, HJPs can also help foster a paradigm shift in which lawyers, academics,

\footnotetext{
${ }^{152}$ They are also referred to as medico-legal partnerships or multi-disciplinary partnerships.

${ }^{153}$ Barry Zuckerman, 'Why paediatricians need lawyers to keep children healthy' (2004) 114 Paediatrics, 224.

${ }^{154}$ Marnie von Wilpert, 'Medico-legal partnerships in Mississippi: A model to improve access to justice' (2013) 82 Supra, 199.

${ }^{155}$ Ibid.
} 
doctors, and 'other healthcare professionals work together for a common good.'156 HJPs offer innovative, effective, and holistic approach to delivering health and legal services. ${ }^{157}$

The number of HJPs in Australia has increased significantly over time. For example, while in 2012 there were only a handful of services self-identifying as HJPs, in 2018, there were 48 services located in almost all states and territories in a range of settings, including hospitals, community health settings and Aboriginal community health organisations; ${ }^{158}$ with UC's health-justice clinic, being one of the first university-based HJPs. Curran's work highlights how HJPs improve overall outcomes for patients/clients. ${ }^{159}$ The value and importance of health-justice partnerships help explain why, as Curran has observed 'there are a number of HJPs in Australia now and they're starting to pop up like mushrooms. ${ }^{160}$

\footnotetext{
${ }^{156}$ Robert Pettignano, Lisa Bliss and Sylvia Caley ‘The Health Law Partnership: A Medical-Legal Partnership Strategically Designed to Provide a Coordinated Approach to Public Health Legal Services, Education, Advocacy, Evaluation, Research, and Scholarship' (2014) 35 (1) Journal of Legal Medicine 57-79, 78.

${ }^{157}$ Alexis Anderson, Lynn Barenberg and Paul R. Tremblay, 'Professional Ethics in Interdisciplinary Collaboratives: Zeal, Paternalism and Mandated Reporting' (2007) 13 Clinical Law Review 659-718, 660; Liz Curran 'A Research and Evaluation Report for the Bendigo Health-Justice Partnership - A partnerships between Loddon Campaspe Community Legal Centre and Bendigo Community Health Service' (Abridged Final Report October 2016)

${ }^{158}$ Tessa Boyd-Caine, 'Health justice partnerships addressing determinants of health' (12 September 2018) online: < https://www.healthjustice.org.au/2018/09/12/health-justice-partnerships-addressingdeterminants-of-health/>.

${ }^{159}$ Curran n 157.

${ }^{160}$ Kim Lester ‘How Lawyers Improve Health Care’ (ANU Reporter Volume 48 N 2)
} 
Utilising law, medical and the students of other professions in HJPs, and, other interdisciplinary approaches to education are becoming an increasingly common approach. ${ }^{161}$ Collaboration between and cross-fertilising the disciplines of future professionals using such approaches can foster positive 'professional attitudes toward collaborating across disciplines [and create] better future attorneys, physicians, nurses, social workers, public health practitioners, health care executives, and other professionals.' 162

\section{B. UC's 'Health-Justice Clinic' Pilot: An Overview}

The University of Canberra (UC) has a small law school which focuses on developing law students' practical skills and offers two law degree programs: a Bachelor of Laws (LLB) and a postgraduate juris doctor (JD) program. Approximately 83\% of law students are enrolled in the LLB and $17 \%$ in the JD program. The law student demographics are diverse at UC, but not unlike many other law schools. There are approximately $53 \%$ of students that are female; $47 \%$ that are male; $8 \%$ of students identify as indigenous; and $42 \%$ of students are 'first generation' university students (that is, the law student is the first member of their family to attend university). ${ }^{163}$

\footnotetext{
${ }^{161}$ Suzanne Weise, 'Defining the role of clinical law students, medical-legal partnerships and probono lawyers' (2018) 13 Tennessee Journal of Law and Policy 18.

162 Pettignano n 156.

${ }^{163}$ University of Canberra, 'Background on University of Canberra law students' policy paper for Course Advisory Committee' (2012); Judy Allen and Paula Baron, 'Buttercup goes to law school: student wellbeing in stressed law schools' (2004) 86 Alternative Law Journal 29(6); Council Australian Law Deans ‘Data Regarding Law School Graduate Numbers and Outcomes' Fact Sheet. November
} 
In June 2017 (Winter semester) the authors established a pilot Health-Justice Legal Advice Clinic (UCH-JLAC) at the University of Canberra, Australia. The UCH-JLAC operated as a collaboration between the School of Law \& Justice, the University's Medical and Counselling Service, and a private law firm. It brought together health professionals (including doctors, psychologists and social workers), legal professionals (including academics, practising lawyers and volunteers) and later year high-achieving law students. ${ }^{164}$

The pilot operated within a clinical legal education context - that is, students were enrolled in a 'legal advice clinic' unit of study and worked under the supervision of practising lawyers to provide legal assistance and support services to clients who, in the main, were referred from the medical and counselling service. During orientation and for the duration of the program, students were, as a group, provided with resilience-building strategies and pastoral care with the support and guidance of psychologist. Students were also particularly encouraged to privately consult with the psychologist if any issues raised during client consultations were in any way triggering

2017201 online: https://cald.asn.au/wp-content/uploads/2017/11/Factsheet-

Law Students in Australia.pdf.

164 The selection process for the pilot clinic involved interested students providing an expression of interest which included a brief summary of their reasons for wanting to participate in the program, together with a copy of their resume and academic transcript. Students were then interviewed by the unit convenors who made a decision based on this information as well as their own subjective assessments as to which students would be a 'good fit' for the program. Since the pilot clinic could only accommodate a very small number of students and because the convenors wanted to give the pilot clinic the best possible chance of success as well as providing an opportunity for those students most likely to benefit from participation, the student cohort selected for participation was inevitably biased towards high-achieving law students who were nearing the end of their studies. 
for them. Students who successfully completed the components of the academic unit (which included completing a reflective journal and making a presentation in addition to attending the clinic and providing client legal services) were awarded 3 credit points towards their degree. After the completion of the unit, feedback was sought from students about their experience of the clinic, and in particular, their exposure to the resilience-building and emotional support provided within the context of the clinic. ${ }^{165}$ Their responses were overwhelmingly positive.

In the context of the pilot, law students were offered an opportunity to appreciate the perspectives of other disciplines and therefore better understand how different disciplinary skills and knowledge might assist in creative problem-solving for the benefit of the client. ${ }^{166}$ At the same time, we considered that by having students focus on solving the problems of others, this work might ameliorate their own stress, ${ }^{167}$ including by offering them the satisfaction of helping others achieve good

\footnotetext{
${ }^{165}$ Ethics approval to survey and interview the students was obtained after students had completed the Legal Advice Clinic unit. Those students who agreed to provide feedback by online survey or through individual interviews with psychologist and unit convenor were required to completed a consent form.

${ }^{166}$ Doris Bozin, Allison Ballard and Vicki de Prazer, 'Interdisciplinary Collaboration to Benefit 'New' and Emerging Lawyers' in Judith Marychurch and Advia Sifris (eds) Wellness for Law Making Wellness Core Business (LexisNexis Butterworths, 2020); Charity Scott, 'Transforming the Future of Public Health Law Education through a Faculty Fellowship Program' (2016) 44, Suppl, 1 The Journal of Law, Medicine \& Ethics 6-17, 14; Margaret Martin Barry, Jon C. Dubin and Peter A. Joy, 'Clinical Education for This Millennium: The Third Wave' (2000) 7 (1) Clinical Law Review 65-71.

${ }^{167}$ Alexis Anderson, Lynn Barenberg and Paul R. Tremblay, 'Professional Ethics in Interdisciplinary Collaboratives: Zeal, Paternalism and Mandated Reporting' (2007) 13 Clinical Law Review 659-718, 661.
} 
outcomes. ${ }^{168}$ Yet the authors also recognised that the students might experience distress when dealing with clients, particularly clients who were likely to have multiple physical and mental health problems on account of being referred from the medical and counselling service. Consequently, we considered that in the context of a clinical legal education setting, incorporating self-awareness raising and resiliencebuilding into the unit design would also be important. The authors also hoped that completing the unit would assist them at university and as future professionals.

Initially, the development of the pilot involved three main steps:

- Identifying, developing and designing a clinical legal education university program, with the assistance of a psychologist, to build resilience individual students during the semester by focusing on developing self-awareness and through their work helping clients in the legal clinic;

- Developing a collaborative approach and working as a team - law academics, legal practitioners and health practitioner staff working together for the benefit of the patient/client, while not breaching any ethical and professional obligations;

- Training the professionals - lawyers providing training and education to doctors, psychologists and social workers about identifying legal issues and

\footnotetext{
168 Joshua D. Rosenberg, 'Interpersonal Dynamics: Helping Lawyers Learn the Skills, and the Importance, of Human Relationships in the Practice of Law' (2004) 58 University of Miami Law Review, 1225, 1228.
} 
health professionals providing information to lawyers and students about recognising mental illness in a patient/client.

The aims of the UCH-JLAC were three-fold and included:

- providing legal practice experience to law students in a safe environment; and

- assessing student resilience at the outset and to provide students with education, tools and ongoing pastoral care to develop their resilience throughout the course of the semester; and

- improving access to justice for vulnerable people through the provision of an independent pro bono community legal service at the university. Client/patients were "warm-referred" from the Medical \& Counselling Service (and also to dropin clients and clients referred from other sources).

C. How Did the Programme Work?

Law students enrolled in a subject ${ }^{169}$ in their law degree, which allowed them to participate in the UCH-JLAC which operated on one day each week with patients/clients referred by health professionals. ${ }^{170}$ The students' clinical education induction and support program involved a series of seminars with a lawyer and a

\footnotetext{
${ }^{169}$ Either the Legal Advice Clinic Unit or a Law Internship Unit.

${ }^{170}$ The relevant health professionals were provided with an education session on 'How to Spot a Legal Issue' prior to the commencement of the UCH-JLAC so that they were able to 'warm refer' appropriate patients/clients.
} 
psychologist, which were held prior to, and after the operation of the UCH-JLAC, on each clinic day.

The induction and support program consisted of three components: induction, debriefing, and evaluation. The induction component involved meeting with a psychologist as a group and participating in a series of Psychological Resilience related exercises. ${ }^{171}$ The development of resilience was aligned to psych-education and reflection on character strengths, emotional challenges and strategies promoting the discovery of professional identity. The psychologist then facilitated a discussion and provided insight into the importance of resilience on a personal and professional level, before giving students an opportunity to discuss their individual Psychological Resilience test results and their reflections. During this initial program, the psychologist focused on resilience as a competency that students should build on at a personal and professional level and provided guidance about what resilience practices and strategies looked like, and how individual resilience could be developed. ${ }^{172}$

The second de-briefing session component had two aspects: student-lawyer interaction and student-psychologist interaction. During the student-lawyer interaction, students and lawyers met to discuss the days' cases with an emphasis on the importance of

\footnotetext{
171 These exercises were made available to students were made available to students on the day of the induction.

172 The psychologist also completed the questionnaires and opened the session by discussing the results of her profile with the group. This was done to make the students feel comfortable about sharing their results with the group.
} 
providing pro bono services to disadvantaged members of the community. The idea that they were doing important, "good" and "real" work was also reinforced. ${ }^{173}$ This provided a context for students to think about their role as future lawyers and legal practitioners, as in some instances there was no legal assistance that the UCH-LJA was able to provide to clients. ${ }^{174}$ The other part of the session involved students discussing with the psychologist their feelings, values and responses in relation to the client interview work.

The students acknowledged that many of the patients/clients had challenging life circumstances and complex mental and/or physical health issues; this often meant containing the interview very difficult. Students indicated that observing the strategies used by the different UCH-JLAC lawyers, including to build rapport and clarify the client's legal issues, was invaluable.

The psychologist sessions encouraged the law students to be more self-aware and reflect on their experience of the case as a resilience-building habit, supported by debriefing as necessary. These sessions also emphasised the evidence around life-style

\footnotetext{
${ }^{173}$ Maren Robinson, 'The Benefits of Volunteerism in the Law' (1998) 42(3) Boston Bar Journal 8. ${ }^{174}$ Mark Heekin, 'Implementing Psychological Resilience Training in Law Incubators, (2015) Experiential Learning 286; Deborah L Rhode, 'Rethinking the Public in Lawyers' Public Service: Pro Bono, Strategic Philanthropy and the Bottom Line, Fordham L Review 1435-1437. A wide range of evidence suggest that selfless action is good for the self; it enhances satisfaction, health and selfesteem. It was important to emphasis in these de-brief sessions to students how important the work they were doing was to the community.
} 
choices as very significant in the building and maintenance of resilience, e.g. good sleep, exercise, healthy diet, low alcohol consumption and close relationships. ${ }^{175}$

The third evaluation ${ }^{176}$ and reflection component of the program was a discussion between the students, lawyers and psychologist of the legal clinical experience. Students, with guidance from the psychologist, discussed strategies and practices they might utilize to build competency in resilience on both a personal and professional level.

By evaluating individual competencies in this way, it was considered that personal and professional confidence, good communication skills and reflective practice would be promoted, in turn leading to the further development and maintenance of resilience. While encouraging students and early career lawyers to speak-up about what they don't understand or can't do may be an anathema to the culture of the profession, this and other strategies may be essential in reducing mental health issues and promoting resilience.

\footnotetext{
175 Mary C Davis, 'Building Emotional Resilience to Promote Health' (2009) 3 (1_suppl) American Journal of Lifestyle Medicine 60S-63S.

${ }^{176}$ The evaluation of the program was done as a group-discussion with the students, lawyers and psychologist, in terms of what students resilience-building strategies that they would use in the future.
} 
Feedback provided by students at the conclusion of the program through face-to-face interviews was positive. ${ }^{177}$ Many students reported that they enjoyed having a psychologist included in the program; that it provided pastoral care, along with resilience-building strategies. They also reported that their overall confidence improved. The authors can only make general comments as to why this approach increased their confidence. It is difficult to surmise why students' confidence improved, and whether it was from the assistance from a psychologist who provided a strong pastoral care program along with resilience-building strategies, the development of their practical legal skills in a legal clinic setting; assisting in delivering a pro-bono community legal service to clients; or a combination of all these factors.

The authors plan to conduct further research as to why this approach increased students' confidence by developing a base-line at the beginning, during and after the program. Additionally, providing students with specific questions about each of the components within the program, should provide more valuable information about the program.

Furthermore, this pilot was extremely resource intensive. The authors will expand the program to make it available to more students by only including the psychologist in

\footnotetext{
${ }^{177}$ Ideally students should have been interviewed at the beginning and during the program. This information would have provided a base-line as to their expectations, skill and knowledge development.
} 
group-discussions on resilience building; (however, if they request it, students would be able to have individual sessions); students completing instruments at beginning and end of program to develop a base-line in relation to their wellness; and a focus on building confidence through understanding the role of a lawyer.

\section{Conclusion}

Improving resilience is an important component of ensuring the mental health and wellbeing of law students, both in the context of their academic studies and as future legal professionals. Building greater resilience is also one way of assisting legal professionals to cope with the significant challenges they face on account of the transformation of legal work. The pilot Health-Justice Clinic at the University of Canberra focused on providing practical legal experience for a small select cohort of law students, while simultaneously offering tools to develop their resilience and understanding of "self", including through a comprehensive orientation program and a strong pastoral care component. The clinic also provided the students with an opportunity to work with, and gain insight into the work of different professions and to develop inter-disciplinary networks. The collaboration between the clinic's psychologist, who focused on providing resilience-building strategies tailored to individual personalities together with a strong pastoral care component, and the clinic's academics/lawyers who provided supervised practical legal experience to allow the students to help deliver a pro-bono community legal service, did assist the students. Offering law students a legal clinical experience with a strong pastoral care 
component and a focus on resilience-building strategies is one possible piece of the mental health and wellbeing in the law jigsaw puzzle. Allowing more students, and a greater range of students, the chance to participate in similar interdisciplinary clinical programs offers a novel approach to improving law student resilience during their academic studies as well as preparing them to stay healthy as they move into legal practice. 